\title{
Factors Affecting Learning Mathematics in the Case Assosa University Collage of Natural Science
}

\author{
Habtamu Shenkut Belhu \\ Department of Mathematics, Assosa University, Assosa, Ethiopia \\ Email address: \\ habtamushenkut@yahoo.com

\section{To cite this article:} \\ Habtamu Shenkut Belhu. Factors Affecting Learning Mathematics in the Case Assosa University Collage of Natural Science. International \\ Journal of Education, Culture and Society. Vol. 2, No. 1, 2017, pp. 6-12. doi: 10.11648/j.ijecs.20170201.12
}

Received: August 17, 2016; Accepted: January 14, 2017; Published: February 21, 2017

\begin{abstract}
This paper was intended to access factors affecting teaching and learning mathematics in Assosa University faculty of Natural and Computational Science (NCS) students. The research method used for study was descriptive survey and supported by qualitatively. The respondents the study were all NCS students (except Biology and Sport science students) and all mathematics instructors. The main purpose of the study was to determine the factors that affect teaching and learning mathematics. Some instruments like questionnaire, focus group discussion (FGD) and interview were employed for data collection. The questionnaires were filled by 80 students and 16 instructors. Furthermore, the researcher held FGD with all one-to-five network group leaders of each section students and all instructors. For interview, 7 students (representatives of each section) and 5 instructors were interviewed. Thus, the findings indicate that demographic, instructional strategies and methods and individual factors affect teaching and learning mathematics. Among these factors instructional strategies and methods was the first most influential factor in teaching and learning mathematics. The second and the third most influential factors are individual and demographic factors respectively. Most respondents have a problem of language, income, arithmetic ability, background knowledge and confidence to understand mathematical concepts. The other main finding was there are no enough materials and facilities in the university for teaching and learning mathematics. But, availability of enough materials and facilities in the university were a factor for teaching and learning mathematics. Finally, based on the findings of the study, it was recommended that students need to be equipped with necessary background knowledge, arithmetic ability and they should developed confidence in mathematics. So, concerned bodies of the university should give a valve able support concerning each factor to increase students' performance in teaching and learning mathematics.
\end{abstract}

Keywords: Factor, Affecting, Learning and Mathematics

\section{Introduction}

\subsection{Backgroundof the Study}

Mathematics is the subject that recognized as the mother of all learning with other subjects deriving their concepts from it, in both arts and sciences. It is also an international language and is essential in almost every field, such as handling money, measurements in fashion and carpentry, technical economics, etc. Mathematics is also regarded as the queen of all sciences, such as chemistry, physics, biology, economics, etc. Mathematics is a way of thinking and organizing a logical proof. It can be used to determine whether or not an idea is true, or at least, whether it is probably true as a way of thinking, as it gives insight into the power of human mind and becomes a challenge to intellectual curiosity. No wonder, any individual who is competent in mathematical sciences, can equally have the ability to do any other course. Consequently, a good performance in mathematics is important. (Oseiwu Ali, 2013).

Furthermore, Ethiopia and the world all over are talking about sustainable development, for which STEMs (science, technology, engineering, and mathematics) cannot be set aside, nor separated from the plans to achieve sustainable development. According to Nwafor (2012), development is a process, in which the people or the beneficiaries are actively involved in deciding what they need and how to provide for them.

As is the case in the past, most people today still believe that mathematics is all about computation. However, computation for mathematicians is merely a tool for comprehending structures, relationships and patterns of 
mathematical concepts, and therefore producing solutions for complex real life problems. This perspective of mathematicians has gained more attention and importance with rapid advancements in information and communication technologies. It becomes necessity for people of all ages to reach, analyze, and apply the mathematical knowledge effectively and efficiently to be successful citizens in our information age. In particular, students need to be wellequipped with higher-order mathematical knowledge.

In this era of globalization and technological revolution, education is considered as a first step for every human activity. It plays a vital role in the development of human capital and is linked with an individual's well-being and opportunities for better living (Battle \& Lewis, 2002). It ensures the acquisition of knowledge and skills that enable individuals to increase their productivity and improve their quality of life. This increase in productivity also leads towards new sources of earning which enhances the economic growth of a country (Saxton, 2000). The quality of students' performance remains at top priority for educators. It is meant for making a difference locally, regionally, nationally and globally. Educators, trainers, and researchers have long been interested in exploring variables contributing effectively for quality of performance of learners. These variables are inside and outside school that affect the teaching and learning process and also students' quality of academic achievement.

These factors include age, gender, geographical belongingness, ethnicity, marital status, socioeconomic status (SES), parents' education level, parental profession, language, income and religious affiliations will discussed under the umbrella of demography. In a broader context demography is referred to as a way to explore the nature and effects of demographic variables in the biological and social context (Ballatine, 1993).

Fromthe above factors, socioeconomic status is one of the most researched and debated factor among educational professionals that contribute towards the academic performance of students. The most prevalent argument is that the socioeconomic status of learners affects the quality of their academic performance. Most of the experts argue that the low socioeconomic status has negative effect on the academic performance of students because the basic needs of students remain unfulfilled and hence they do not perform better academically (Adams, 1996). The low socioeconomic status causes environmental deficiencies which results in low self esteem of students (US Department of Education, 2003).

\subsection{Statement of the Problem}

My country Ethiopia has planed and striving to achieve the quality of education at each level. But, there are many types of problems that affect the teaching and learning process. Particularly, at the University level there are many factors; like students background, facilities such aswell organized library, class rooms conditions teaching and learning materials, offices and soon are some factors for teaching learning that affect the teaching and learning process specifically teaching learning mathematics. Due to this, the students' performance decreases in mathematics from year to year. Thus, my research will fill the gap that is identifying and examining those factors affecting teaching and learning mathematics.

Those factors in teaching and learning mathematics, are divided into three sub categories: Demographic Factors (gender, socio-economic status, parent's educational level), Instructional Factors (teacher competency, instructional strategies and techniques, curriculum, school context and facilities), and Individual Factors (self-directed learning, arithmetic ability, motivation).

It is important for educators and teachers to adopt instructional design techniques to attain higher achievement rates in mathematics. (Rasmussen \& Marrongelle, 2006). Considering students' needs and comprehension of higher-order mathematical knowledge, instructional design provides a systematic process and a framework for analytically planning, developing, and adapting mathematics instruction (Saritas, 2004).

Instructional design alone cannot produce better learning and students' achievement. The instructional designer must know crucial factors that affect student learning and build a bridge between goals and student performance. Identifying these factors will help to utilize limited resources including financial resources and time more effectively (Libienski \& Gutierrez, 2008).

In an effort to understand the factors associated with teaching learningmathematics, researchers have focused on many factors. (Beaton \& Dwyer, 2002; Kellaghan \& Madaus, 2002; Kifer, 2002). The impact of various demographic, social, economical and educational factors on students' mathematics achievement continues to be of great interest to the educators and researchers. For instance, Israel et al. (2001) concluded that parents' socioeconomic status is correlated with a child's educational achievement. Another study by Jensen and Seltzer (2000) showed that factors such as individual study, parents' role, and social environment had a significant influence on "further education" decisions and achievements of young students'. In another study, Meece, Wigfield \& Eccles (1990) investigated cognitive motivational variables that influence students' decisions to enroll in advanced math courses. Their findings revealed that math ability perceptions affect students' valuing of math and their expectations for achievement.

\subsection{Research Questions}

The study was proposed four main research questions.

1. To what extent demographic factors influence the learning mathematics?

2. How do instructional factors influence the learning mathematics?

3. To what extent and how individual factors influence the learning mathematics?

4. Which factor is the most influential factor on learning mathematics?

\subsection{Objective of the Study}

The study washaving the following general and specific 
objectives. The ultimate objective of the study was to assess the factors affecting learning mathematics in Assosa University.

The specific objectives of the study were:

- To identify the demographic factors those influence the learning mathematics in Assosa University.

- To determine instructionalfactors those influence the learning mathematics in Assosa University.

- To identify individual factors those influences the learning mathematics in Assosa University.

- To identify the most influential factor for learning mathematics in Assosa University.

\section{Methodology}

\subsection{Research Design}

This research was an aim of assessing factors affecting the teaching and learning mathematics in Natural and Computational Science at Assosa University. This study was employ descriptive survey method.

\subsection{Study Area}

Benishangul-Gumuz region is one of the regions of Ethiopia. According to the 2007 population and housing census conducted nationwide the population of the Benishangul-Gumuz region was 784,345 (398,655 male and 385,690female). Assosa town, which is one of the border towns of Ethiopia, is the capital of Benishangul-Gumuz regional state. More to the point, Assosa University, is one of Ethiopian University which is found in Benshangul-Gumuz region particularly in Assosa town and established in 2001 E. C.

\subsection{Sampling, Data Collection and Analysis}

All Natural and Computational Science Faculty students 433 (257males and 176 females) were the population of the study. In addition to this all $16(15$ males and 1 female) mathematic department teachers including the department head were also directly participate in the study as a participant. This faculty was selected purposively for the researcher research title, factors affecting teaching and learning mathematics and the researcher also one of mathematics instructor which faced problems in teaching and learning mathematics. Therefore, the researcher 80(40 male and 40 Female) students were selected using quota sampling technique as a sample and it is easy to manage and to collect the require data from the population. Thus, 80 students (all sample members are group leaders of each section) and 16 teachers were used as a sample. For interviewee 7 students (representatives of each section for each departments) and 5 teachers were select and interview.

Qualitative and quantitative data types were gathered from primary data sources on issues of factors affecting teaching/learning mathematics.

In order to achieve the objectives of the study, the data were collected through questionnaire, focus group discussion (FGD) and interview. The study was administering FGD for one-to-five group network leaders to each of the selected elements of the study. Additionally, selected participants were interviewed.

This study was conducted on the bases of descriptive studies because the researcher need to study who, what, when, where, how of the topic and stating something about based on the finding of the analysis of the data. Therefore, the researcher was use different analysis procedures like mean, frequency and percentage.

\section{Result and Discussion}

In this chapter, the results obtained from the questionnaire and interview was analyzed. Statistical methods were employed to present and analyze the structured items of the questionnaire quantitatively. To supplement and enrich the information that was drown using a questionnaire, the data from closed and open ended questions and interview were analyzed and described qualitatively.

\subsection{Results on Demographic Factors Influence the Learning Mathematics}

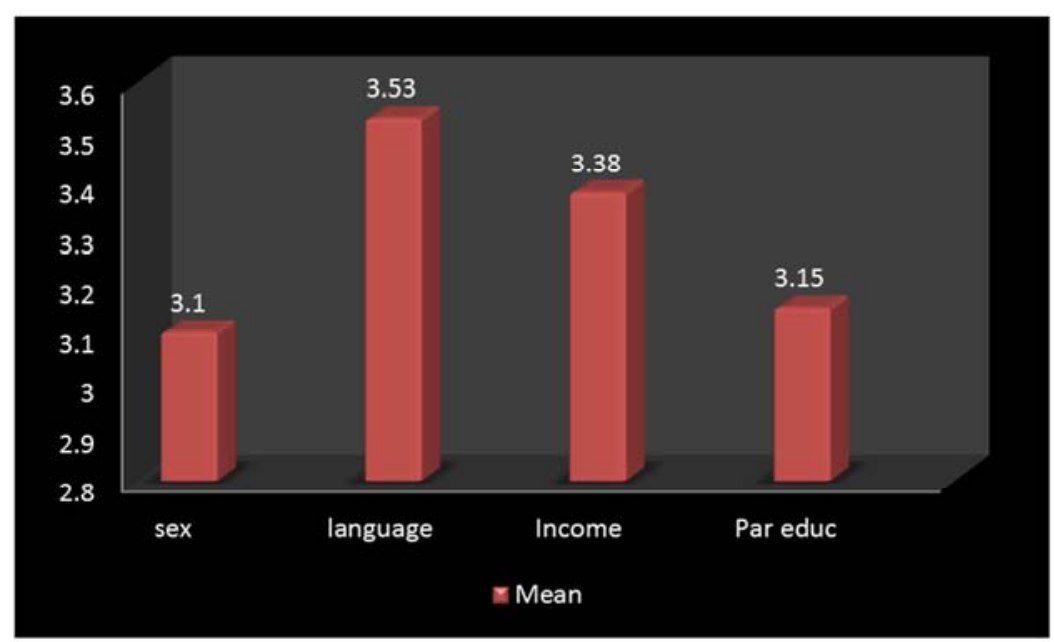

Figure 1. Total response for demographic factors. 
As can be seen from the above figure (figure 1) the result obtained from the respondents revealed that the most influential demographic factor is language problem 141(mean, 3.53) to understand mathematical concepts. The second most influential factor is students' income, the third is students' parent education level and the last factor is sex which means males can understand mathematical concepts more than females.

\subsection{Results on Instructional Factors Influencing the Learning Mathematics}

Table 1. Respondents' response on instructional factors.

\begin{tabular}{|c|c|c|c|c|c|c|c|c|}
\hline \multirow[t]{2}{*}{ No. } & \multirow[t]{2}{*}{ Statement } & \multirow[t]{2}{*}{ Sex } & \multicolumn{2}{|c|}{ Disagree } & \multicolumn{2}{|c|}{ Undecided } & \multicolumn{2}{|c|}{ Agree } \\
\hline & & & $f *$ & $\%$ & f & $\%$ & f & $\%$ \\
\hline \multirow{2}{*}{1} & \multirow{2}{*}{$\begin{array}{l}\text { Mathematics curriculum focus on memorization of facts and proof besides its } \\
\text { application }\end{array}$} & $\mathrm{M}$ & 12 & 30 & 3 & 7.5 & 25 & 62.5 \\
\hline & & $\mathrm{F}$ & 11 & 27.5 & 3 & 7.5 & 26 & 65 \\
\hline \multirow{2}{*}{2} & \multirow{2}{*}{ Instructional strategies and methods also affectlearning mathematics. } & M & 6 & 15 & 4 & 10 & 30 & 75 \\
\hline & & $\mathrm{F}$ & 3 & 7.5 & 2 & 5 & 35 & 87.5 \\
\hline \multirow{2}{*}{3} & \multirow{2}{*}{ There is enough materials and facilities in the university for learning mathematics } & M & 34 & 85 & 3 & 7.5 & 3 & 7.5 \\
\hline & & $\mathrm{F}$ & 34 & 85 & 5 & 13 & 1 & 2.5 \\
\hline \multirow{2}{*}{4} & \multirow{2}{*}{$\begin{array}{l}\text { Availability of enough materials and facilities in the university are factors } \\
\text { oflearning mathematics. }\end{array}$} & M & 7 & 17.5 & 2 & 5 & 31 & 77.5 \\
\hline & & $\mathrm{F}$ & 7 & 17.5 & 3 & 7.5 & 30 & 75 \\
\hline
\end{tabular}

$\mathrm{f}^{*}=$ frequency

Majority of the respondents' $(\mathrm{M}, 25$ or $62.5 \%$ and F, 26 or $65 \%$ ) agreed on the statement that "mathematics curriculum focused on memorization of facts and proofs besides its application" and few of them (3 or 7.5\% of both males and females) did not show the agreement or disagreement on the issue. but, some of the respondents disagree on the idea that mathematics curriculum focus on memorization rather than its applications (table 1, item 1).

item 2 in table 1, shows most of the respondents'(M 30 or $75 \%$ and F, 35 or $87.5 \%$ ) agreed on the issue that instructional strategies and methods can affect teaching and learning mathematics but some of them disagreedon the issue.

Almost all of the respondents (item 3 of table 1) disagreed on the idea that 'in the university, there are enough materials

\subsection{Result on Individual Factors Influence the Learning Mathematics}

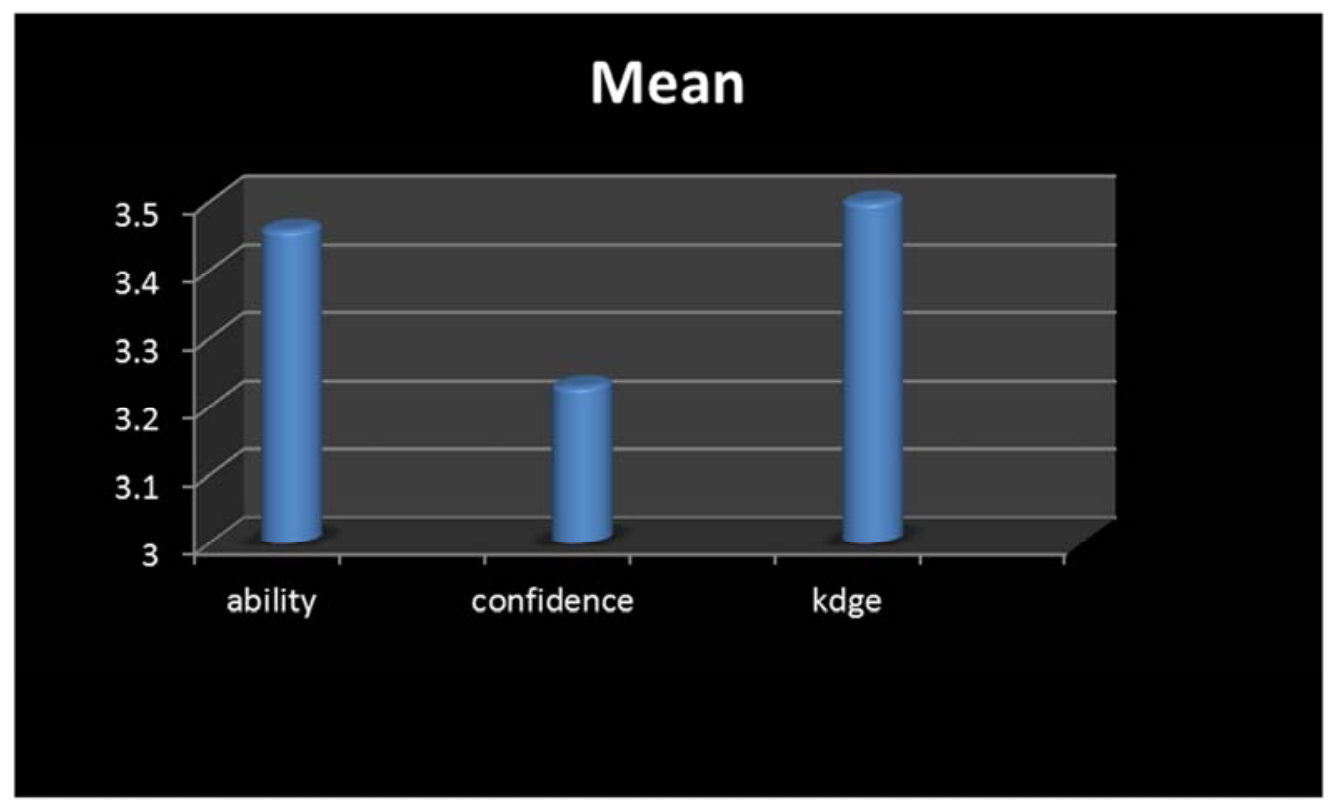

Figure 2. Total response on individual factors. and facilities for teaching and learning mathematics'. But, few of them $8(20 \%)$ did not show the agreement or the disagreement of the statement. In addition, most of the respondents (M, 30 or $75 \%$ and $F, 31$ or $77.5 \%$ ) agreed that availability of enough materials and facilities are a factor for teaching and learning mathematics. However, some of them ( $17.5 \%$ of both M\&F) disagreed on the idea.

The result obtained from FGD and interview showed that all curriculum, instructional strategies and methods and availability of enough materials and facilities in the university are factors of learning mathematics. In addition to this, figure 2 below shows that among these instructional factors, instructional strategies and methods (Mean, 3.91) is the first most influential factor. 
The result obtained from FGD and interview revealed that individual factors also have a great effect in learning mathematics. Among these factors which are shown in the above figure for learning mathematics background knowledge (total sum 159 and Mean 3.5) is the most and the first influential factor, the second and the third are arithmetic ability and confidence respectively.

\subsection{Results on Most Influential Factor in Learning Mathematics}

To answer the last research question "Which factor is the most influential factor in learning mathematics?" the researcher summarized and analyzed the data as follows.

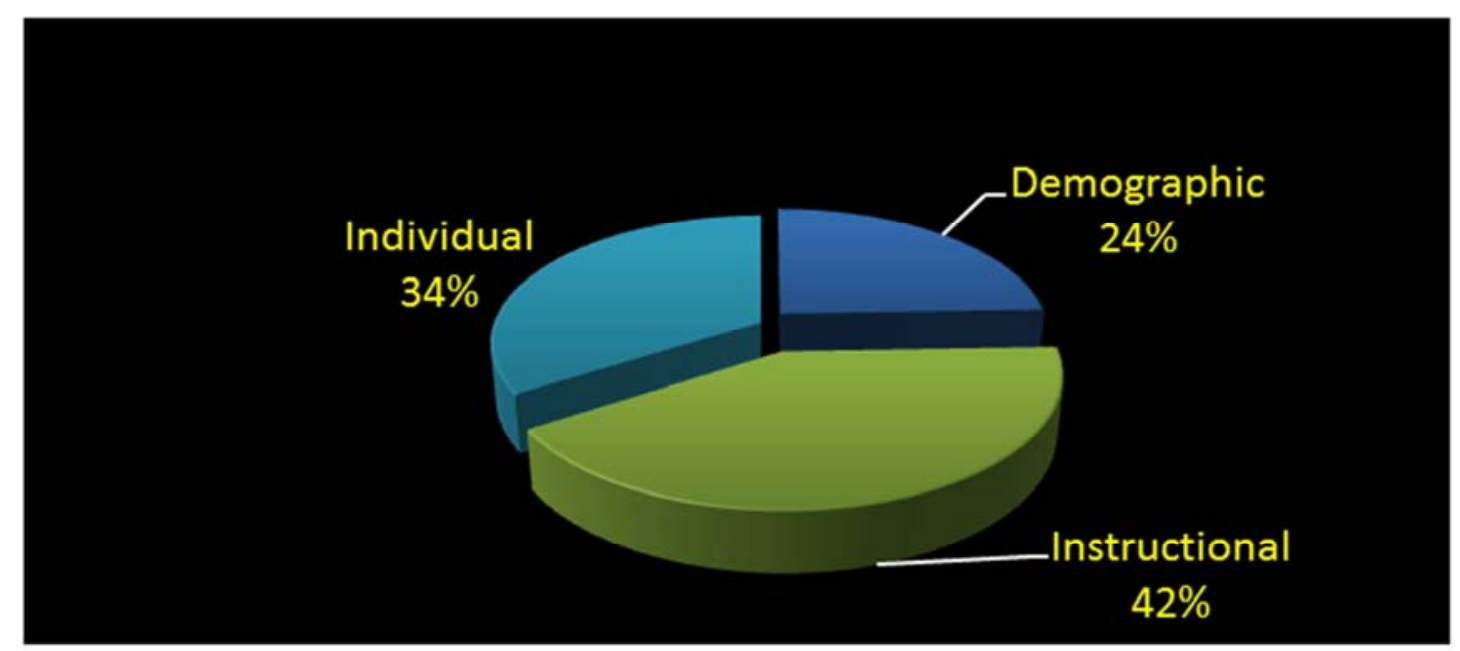

Figure 3. General response on most influential factor.

The above figure showed majority of the respondents (42\% or $\mathrm{M} 4.25$ ) responded that instructional strategies and methods is the most influential factor in learning mathematics. The second and third influential factors are individual $(34 \%$ or mean 3.48$)$ and demographic $(24 \%$ or mean 2.5) factors respectively. In addition to this, the results obtained from FGD and interview also supporting and strengthening the above result.

Summary/Major Findings

The major findings of this study were:

- Results from questionnaire showed that majority of respondents are agreed on the idea that 'males can understand mathematical concepts than females'. Additionally, the result collected from instructors, FGD and interview revealed that males can understand mathematical concepts than female students.

- Mostof the respondents both males and females reported that they faced a language problem to understand concepts and to communicate with instructors in learning mathematics. As the respondents mentioned, the main cause of this problem was most of the students enrolled to the faculty were come from the same region and they are poor to communicate in English.

- Majority of both male and female respondents' respond that income affects the learning mathematics.

- For parents' education level, majority of respondents agreed on the idea that parents' education level affects the learning mathematics.

- The result obtained from the respondents revealed that the most influential demographic factor is language problem to understand mathematical concepts. The second most influential factor is students' income, the third is students' parent education level and the last factor is sex which means males can understand mathematical concepts more than females.

- Almost all of the respondents disagreed on the idea that in the university, there are enough materials and facilities for learning mathematics.

- The result obtained from respondents showed that all curriculum, instructional strategies and methods and availability of enough materials and facilities in the university are factors of learning mathematics. In addition to this, among these instructional factors, instructional strategies and methods is the most influential factor.

- Most of the respondents' agreed that they have a problem of background knowledge, arithmetic ability and confidence in learning mathematics. From these factors background knowledge is the most and the first influential factor, the second and the third are arithmetic ability and confidence respectively.

\section{Conclusion}

In general this study revealed that, there are many factors that affect learning mathematics at Assosa University in natural and computational science students. Most of respondents and instructors agreed that demographic, instructional strategies and methods and individual factors are the most influential factors in learning mathematics. Based on the above major themes the 
following concluding points are made.

- The results revealed that majority of the respondents accept the idea that males can understand mathematical concepts than females. Similar to this, the results from different studies showed that mathematical understandings of each gender group were close to each other at the primary and middle schools. But, there is a significant difference between males and females higher levels to understand mathematical concepts (Campbell, 1995; Lamon, 1990; Gray, 1996; Martin, Goldberg and Stemler, 2000).

- As the result showed language problem is the first most influential demographic factor, income and parents education level are the second and the third influential factors. In addition, many studies also agreed that these factors are affect learning mathematics (Hombe, Campbell \& Mazzeo, 2000; Mc. Neal, 2001; Jwynes, 2002; Eamon, 2005).

- All curriculum, instructional strategies and methods and availability of enough materials and facilities in the university are factors of learning mathematics. Many researchers also found that to precede learning mathematics and to increase students' achievement these factors should be considered (Harner, 1974; Bloom B. 1976; Cobb et al., 1992).

- The results obtained from respondents' revealed that individual factors also one of the most influential factor. From these factors background knowledge is the most and the first influential factor, the second and the third are arithmetic ability and confidence respectively. for instance, researchers agreed that learning mathematics requires highly motivated students because it requires reasoning, making interpretations, solving problems and understanding concepts (Kaeley, 1993; Schiefele \& Cskszentmhalyi, 1995; Broussard and Garrison, 2004 ).

\section{Recommendation}

Based on the above summary and conclusion, the researcher suggests the following possible measures so that the present problem concerning factors affecting learning mathematics in Assosa University could be minimize.

- The University or the faculty if Natural and Computational Science should createconducive environment and give support (arranging and giving tutorial for each mathematics courses) for female students in order to increase and develop their understanding of concepts in mathematics.

- Students have a language problem to understand concepts in learning mathematics. And also they came from poor family so they have a shortage of income. Thus, the university and concerned bodies should consider these problems and find a solution to enhance their performance in mathematics.

- Availability enough materials and facilities in the University are factors of teaching and learning mathematics. So, concerned bodies of the University should arrange enough materials and facilities to develop the learning mathematics.

- Teaching strategies and methods also a factor for teaching and learning mathematics. Therefore, mathematics instructors and curriculum designers should appropriate teaching methods for each topic to increase students' mathematical achievement.

- Students background knowledge, confidence and arithmetic ability have a great impact on students performance in mathematics. so, Ministry of Education, university and students their own self consider these factors and find possible solution to increase audients performance in mathematics.

- Students should get awareness how they study and understand mathematical concepts and how to tackle problem that face them in learning mathematics.

- Finally, further research should be conducted on the entire University including all faculties since it could be difficult to generalize the current finding to all students of the university.

\section{Acknowledgments}

First of all, I would like to express my heartfelt thanks to my almighty God from starting to finish this paper. Secondly, I would like to extend my gratitude for my wife Mrs. Yenanesh Esmelealem and my staff members who are always besides me to give me the kind of insightful and critical comments to the realization of this work.

Last but not least, I would extend my thanks for Assosa University research and community service who give me material and financial support for conducting this work.

\section{References}

[1] Sikiru, Amoo, Akeem (2012) School Environmental Factors and Mathematics Teaching Effectiveness: Implication for ELearning.

[2] M. S. Faroop, A. H. Chaudhry, M. Shafiy, G. Berhanu (2011) Factors Affecting Students' Quality of Academic Performance: Volume VII, Issue II, December, Page 01 - 14

[3] Battle, J., \& Lewis, M. (2002). The increasing significance of class: The relative effects of race and socioeconomic status on academic achievement. Journal of Poverty, 6(2), 21-35.

[4] Saxton, J. (2000). Investment in education: Private and public returns. Retrieved from http://www.house.gov/jec/educ.pdf.

[5] Crosnoe, R., Johnson, M. K., \& Elder, G. H. (2004). School size and the interpersonal side of education: An examination of race/ethnicity and organizational context. Social Science Quarterly, 85(5), 1259-1274.

[6] Ballatine, J. H. (1993). The sociology of education: A systematic analysis. Englwood Cliffs: Prentice Hall.

[7] Blevins, B. M. (2009). Effects of socioeconomic status on academic performance in Missouri public schools. Retrieved from http://gradworks.umi.com/3372318.pdf 
[8] Adams, A. (1996). Even basic needs of young are not met. Retrieved from http://tc.education. pitt.edu/library/SelfEsteem

[9] Parri, J. (2006). Quality in higher education. Vadyba/Management, 2(11), 107-111.

[10] US Department of Education. (2003). Confidence: Helping your child through early adolescence. Retrieved from http://www.ed.gov/parents/academic/help/adolescence/part8.ht $\mathrm{ml}$

[11] Lamb, Stephen and Fullarton, Sue, "Classroom And School Factors Affecting Mathematics Achievement: a Comparative Study of the US and Australia Using TIMSS" (2001).

[12] Hay Mc Ber (2000). Research into teacher effectiveness. Report for the Departmentof Education and Employment, UK.

[13] Anderson, L. W., Ryan, D. W., \& Shapiro, B. J. (1989). The IEA classroomenvironment study. Oxford: Pergamon Press.

[14] Larkin, A. I., \& Keeves, J. P. (1984). The class size question: A study at different levels of analysis. Hawthorn: Australian Council for Educational Research.

[15] Lee, V. E., \& Smith, J. B. (1997). High school size: Which works best and for whom?i. Education Evaluation and Policy Analysis, 19(3), 205 - 228.
[16] Fullarton, S. \& Lamb, S. (2000). Factors affecting mathematics achievement in primary and secondary schools: Results from TIMSS. In J. Malone, J. Bana \& A. Chapman (Eds.), Mathematics education beyond 2000 (Proceedings of the 23rd annual conference of the Mathematics Education Research Group of Australasia, 2000). Perth, WA.

[17] Oseiwu Ali (2013)Factors Affecting Students' Academic Performance in Mathematical Sciences Department in Tertiary Institutions in Nigeria Kogi State University, Anyigba, Nigeria

[18] Nwafor, M. O. (2012, November 12th-16th). Components of education for sustainable peace. Lead paper presented at 2012 Biennial Conference organized by Faculty of Education, Cross River State University of Technology, Calabar in Collaboration With School of Education, and Nwafor Orizu College of Education, Nsugbe.

[19] Team of Mathematics Teachers. (2013). Factors affecting students academic performance in mathematics in Nairobi. Retrieved May 5, 2013, fromhtttp://www.google.com/search?q=factors+affecting+stud ents + performance + in + mathematics $\&$ ie $=$ utf. 8 \&oe $=$ utf.8\&rls $=$ org.non

[20] Yamane, T. (1967) "Statistics: An Introductory Analysis", 3rd ed., New York: Harper and Row. 